\title{
フーリエ変換を用いた斑柄にステップ送りのあるデザインへの展開方法
}

\author{
株式会社 島精機製作所 グラフィックシステム開発部 古金谷圭三・藤崎浩孝 \\ 和歌山大学システム工学部 藤垣元治 \\ 一般社団法人 モアレ研究所 森本吉春
}

\section{Designing Method for Seamless Pattern of Spotted Image with Step Repeat by Using Fourier Transform}

\author{
Keizo Koganeya $^{* 1}$, Hirotaka Fujisaki ${ }^{* 1}$, Motoharu Fujigaki ${ }^{* 2}$, and Yoshiharu Morimoto ${ }^{* 3}$ \\ ${ }^{*}$ Graphic System Development Div., Shima Seiki Mfg., Ltd., 85 Sakata, Wakayama 641-8511, Japan \\ ${ }^{* 2}$ Faculty of System Engineering, Wakayama University, 930 Sakaetani, Wakayama 640-8510, Japan \\ ${ }^{* 3}$ Moire Institute Inc., 2-1-4-804, Hagurazaki, Izumisano-shi, Osaka 598-0046, Japan
}

\begin{abstract}
In textile design, it is often necessary to make a seamless pattern with repeat. The pattern can be designed by using a computer software. By the way, in the case of the geometric design such as the spotted image, the making seamless pattern requires manipulation while considering the continuity of pattern from top to bottom and from side to side. After the inverse conversion is applied only to the areas of low frequency by FFT, the converted image has the continuity from top to bottom and from side to side. This paper proposes the method of making the seamless pattern with repeat by using this characteristic and some image processing.
\end{abstract}

(Received 10 August, 2010 ; Accepted 18 November, 2010)

\section{1. 緒 言}

テキスタイルデザインにおいて, 工業製品のプリント 生地などでは, 単位ユニットの柄(基本柄)が連続になる ように設計されている。 それは, 生地製品が, 長さが 50 $\mathrm{m}$, 幅が $2 \mathrm{~m}$ などの規格なので, 基本柄を上下左右にリピー トして対応しているからである.ささらに, 基本柄のリピー トが簡単に見分けられないように，ハープステップなど のステップ送りと言われる技法が用いられる $[1,2]$.

このような送りの技法も含めた基本柄の作成について は，専用ソフトもあるが，一般のペイントソフトを使っ て, 素材をマニュアルでレタッチしたり, 個々のモチー フを配置したりする手法が示されている[3].

上記の方法で, 例えば迷彩柄のような幾何学的な図案 を元に基本柄を作成する場合には, 柄の上下左右が連続 するようにマニュアルでの描画作業が必要になる。この ように, 幾何学的な柄をリピートさせるには手作業が多 くなり, 効率よくステップ送りのある図案を制作するこ とは困難であった.

ところで, FFT(Fast Fourier Transform)は, 画像処理に おける周波数フィルタリングとしてよく用いられていて [4,5], エンボス加工画像, コントラスト強調画像の処理
などに使われている $[6]$. さらに, フーリエ変換の特徵と して, 低周波成分のみを逆変換すると, 上下左右が連続 する，いわゆるリピートした図案が得られる[7].

しかし，フーリエ変換の低周波成分を使う手法では, 上下左右に連続する四方送り(タイルパターン)の作成に は利用できるが, そのままではステップ送りの眓案には 適用できず，これまでステップ送りの図案作成を示した 例はみられない。

本研究では, この特徵を利用して, 斑(迷彩)柄のよう な幾何学柄に対して, フーリエ変換を利用したステップ 送りの図案(基本柄)への展開方法を提案する.

\section{2. 四方送りとステップ送りの図案}

四方送りの図案を Fig. 1 に, ステップ送り(縦ハーフス テップ)のある図案を Fig. 2 に，それぞれ示す. それぞれ， 左側が基本柄であり, 右側の展開柄の点線で囲まれた部 分と一致している.

Fig. 1 の四方送りの図案の場合, 柄は上下左右に直接連 続していて, リピートが比較的簡単にわかる, という短 所がある. Fig. 2 のステップ送りの図案の場合, 柄が縦も しくは横方向に, その一辺の長さの一定比率分だけシフ 


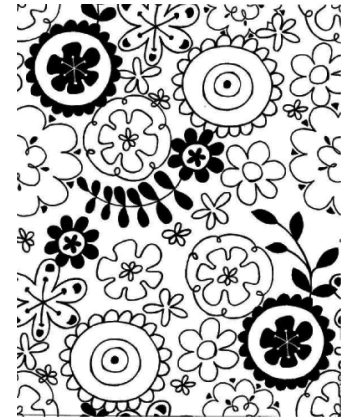

(a) Basic pattern.

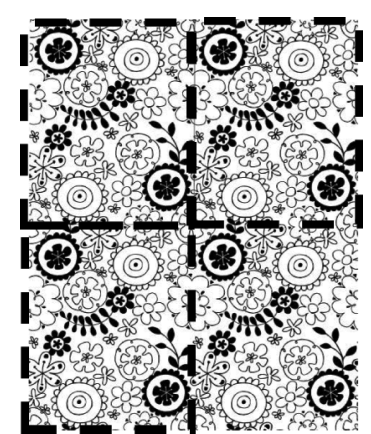

(b) Developing pattern.
Fig. 1 Example for tile pattern.

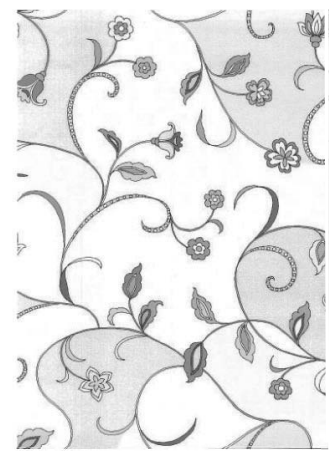

(a) Basic pattern.

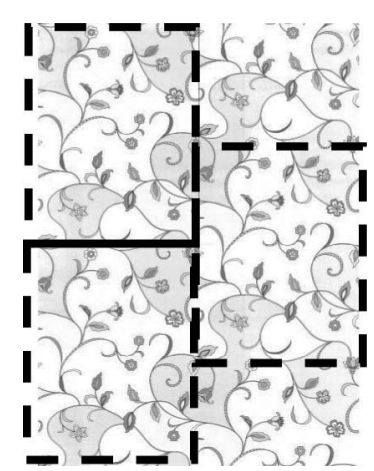

(b) Developing pattern.
Fig. 2 Example for stepped repeat.

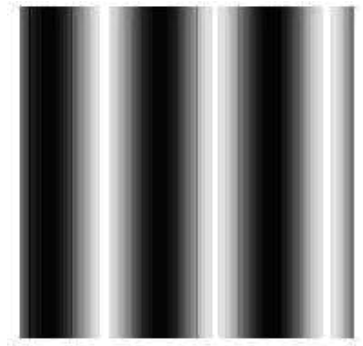

(a) Image.

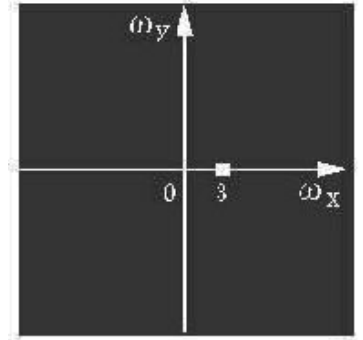

(b) Fourier power spectrum.
Fig. 3 Fourier transform.

トした状態で接続していてリピートがわかりにくく，ダ イナミックに見えるという特徵がある.

\section{3. フーリエ変換による四方送り図案の作成}

\section{1 フーリエ変換}

画像の加工, 編集等の処理でよく使われる FFT につい て, その画像平面と周波数平面とは, Fig. 3 のように対応 づけられる[7].

なお, 関数 $f(x, y)$ のフーリエ変換式と逆フーリエ変換 式はそれぞれ(1)式，(2)式で表わされる.

$$
\begin{aligned}
& G\left(\omega_{x}, \omega_{y}\right)=\int_{-\infty}^{\infty} \int_{-\infty}^{\infty} f(x, y) e^{-i 2 \pi\left(\omega_{x} x+\omega_{y} y\right)} d x d y \\
& f(x, y)=\int_{-\infty}^{\infty} \int_{-\infty}^{\infty}\left\{G\left(\omega_{x}, \omega_{y}\right) e^{i 2 \pi\left(\omega_{x} x+\omega_{y} y\right)}\right\} d \omega_{x} d \omega_{y}
\end{aligned}
$$

フーリエ変換は, Fig.3 (a)で示すような画像データを, (1) 式で積分して Fig. 3 (b) に示すような周波数データに変 換する。 また，逆フーリエ変換は，周波数デー夕を(2)式 で積分して，画像データに逆変換する.

上下左右に図案の連続性を得るには，低周波の領域だ けを利用する。したがって，画像をフーリエ変換で周波 数データに変換, その周波数デー夕に対してローパスフィ ルタをかけて，画像デー夕に逆変換する，すなわち， Fig. 3 (b) の原点近くの領域のデータだけを逆変換する.

\section{2 四方送り図案の作成}

フーリエ変換を用いた四方送り図案作成用の元の図案 は，斑を模した図案である。なお，画像サイズはFFTに 適したサイズとした，それを 3.1 節に示したフーリエ変換, ローパスフィルター, 逆変換, さらに2 值化処理を行っ たそれぞれの処理画像を, Fig. 4 に示す。ローパスフィル ターとして, Fig. 4 (b)に示すように $\omega x=50, \omega y=50$ を闇 值とする円形領域内側を残すフィルターを用いた。 また 2 值化処理は画像全体の平均明度值を闇值として行った。

さらに, Fig. 4 (a) に示す元の図案と, Fig. 4 (d) に示す出 来上がりの図案を, 上下左右にリピートした展開図を Fig. 5 および Fig. 6 にそれぞれ示す.

Fig. 5 から, Fig. 4 (a)に示した元の図案は, 上下左右に 連続性がなかったことがわかる. Fig. 6 の展開図からは, Fig. 4 (d) に示す FFT を使って処理した図案の柄が上下左 右に連続していることがわかる. しかしながら, この図 案と Fig. 4 (a)に示す元の図案を比較すると, 元の図案の 細かく変化しているところは省かれている.

このような元の図案から，FFTを用いてオリジナルの 細かい部分が省かれた上下左右に柄が連続する四方送り 図案が作成できることが示せた。 なお, 逆変換直後の Fig. 4 (c)の (展開)図案も上下左右に連続性がある.

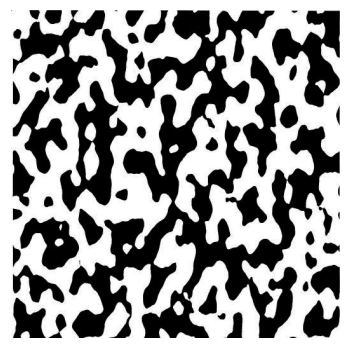

(a) Original image.

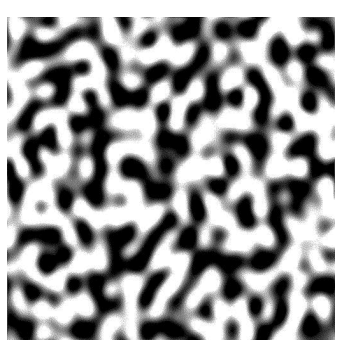

(c) Image by inverse FFT.

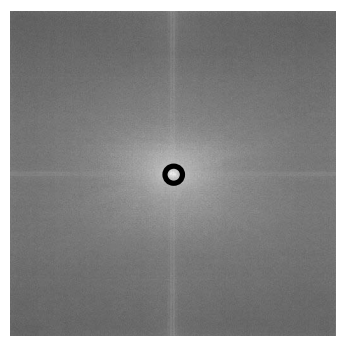

(b) Fourier power spectrum \& filtering (circle).

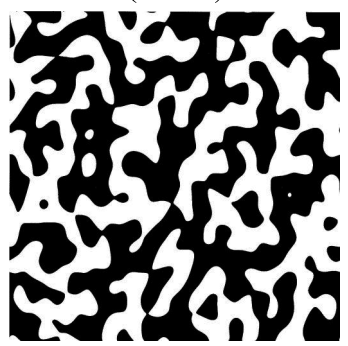

(d) Binarized image (Finished image).
Fig. 4 Image processing by using FFT and binarizing. 


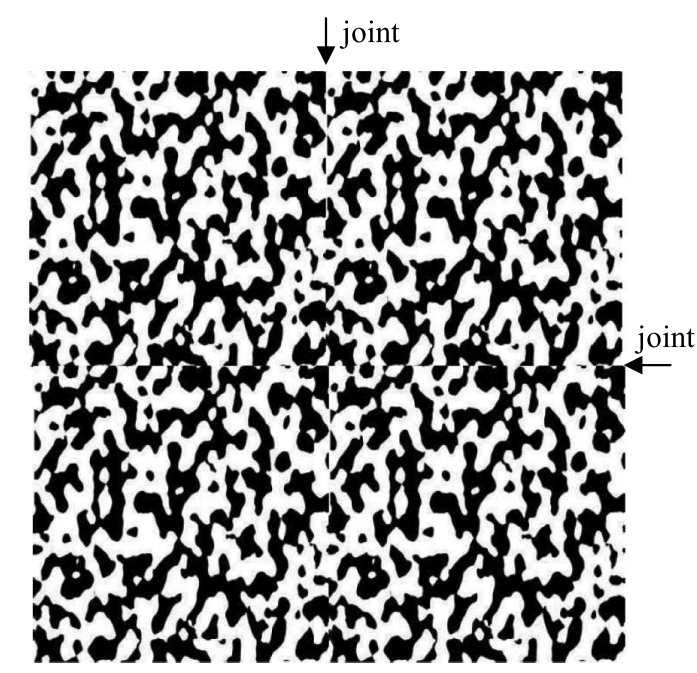

Fig. 5 Original patterns in sequence.

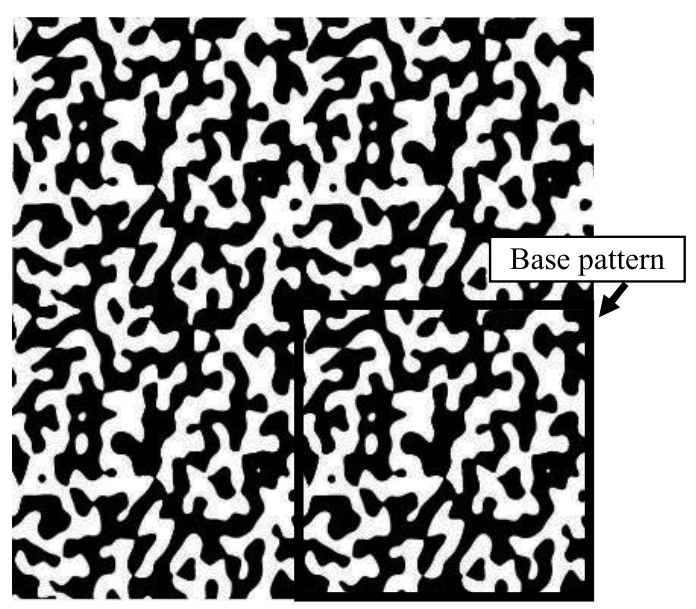

Fig. 6 Seamless pattern with tile step.

\section{4. ステップ送りのある図案の作成}

ここで用いた元の図案は, 斑を模した縦横比 $2: 3$ の画 像である。これから, ステップ送りのある図案の作成, 展開までの処理画像を, Fig.7 (a)〜(1)に示す.

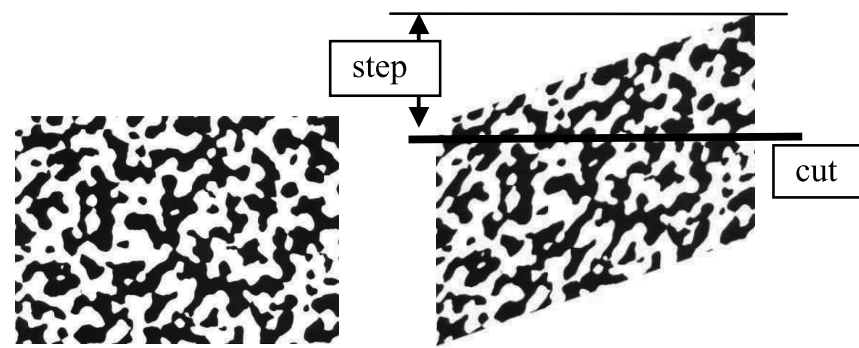

(a) Original image.

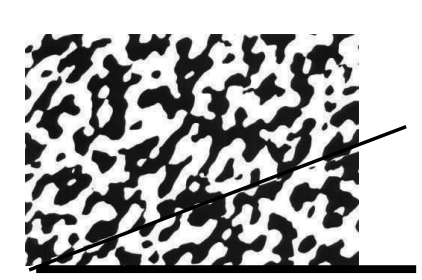

(c) Pasting. (b) Parallelogram deformation \& cut.

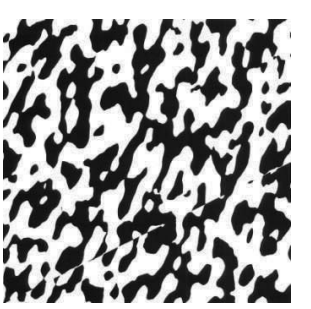

(d) Changing size for FFT.

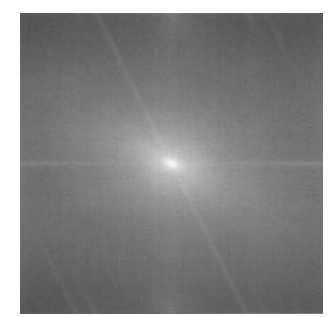

(e) Fourier power spectrum.

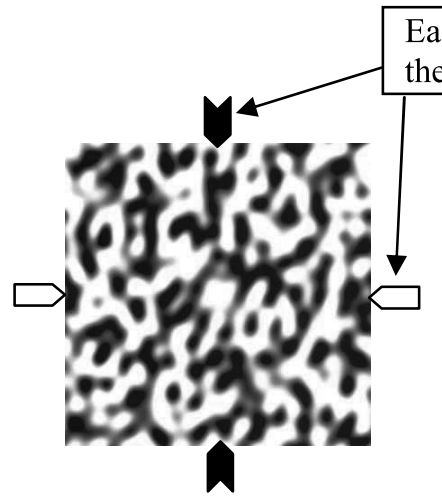

(g) Image by inverse FFT.

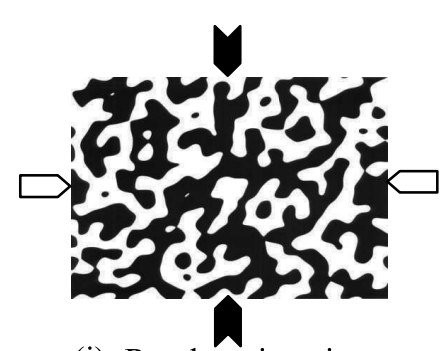

(i) Re-changing size for original.

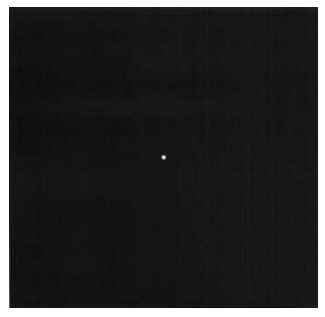

(f) Filtering.

Each pair of arrows shows he continuity of pattern

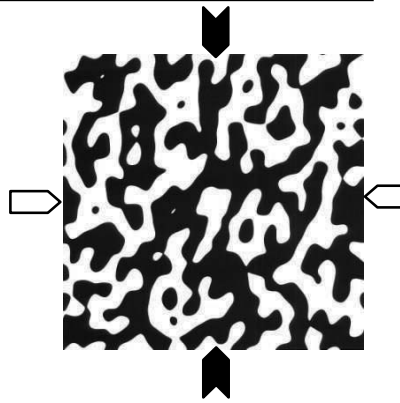

(h) Binarized image.

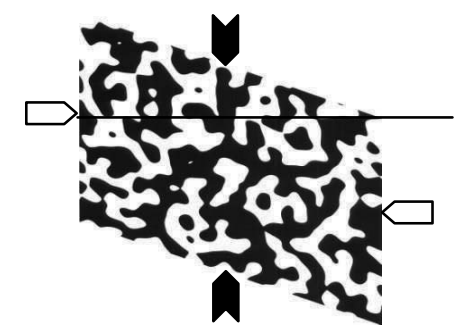

(j) Re-parallelogram deformation \& cut.

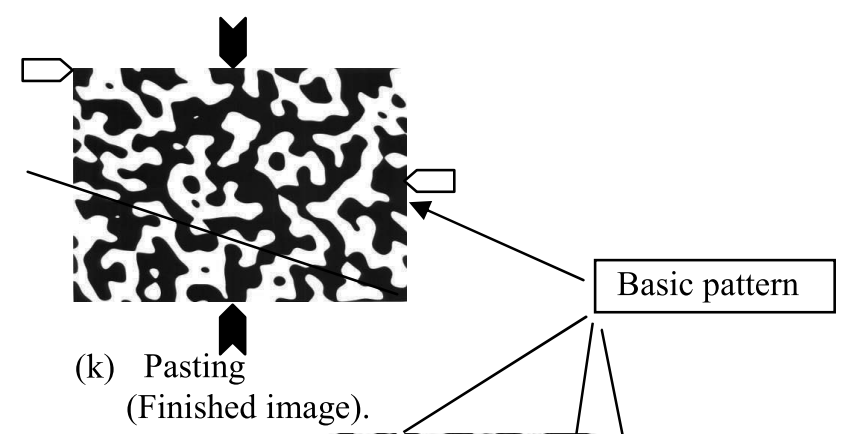

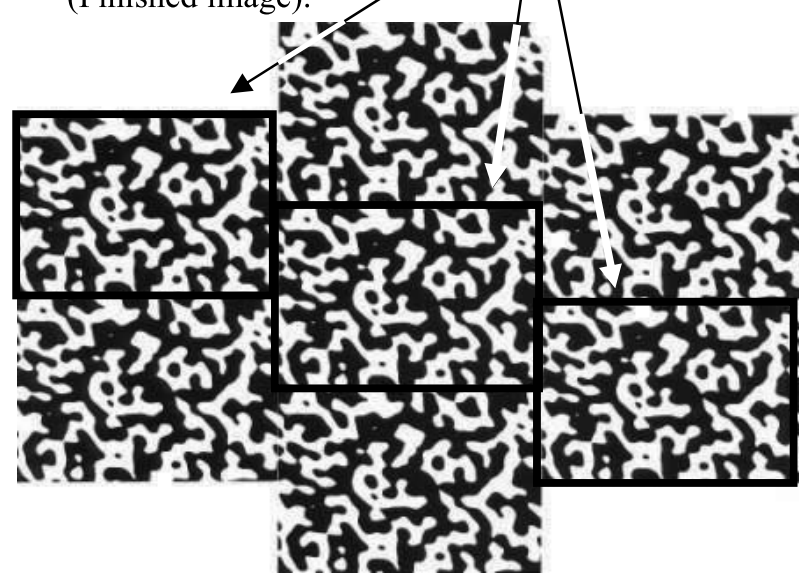

(1) Seamless pattern with stepped repeat.

Fig. 7 Procedure of image processing for stepped repeat. 
展開図(1)をみれば, 斜め方向に柄が連続していて, 出 来上がりの図案 $(\mathrm{k})$ が Fig.2 と同じ, 縦ハーフステップ送 りになっていることがわかる. 図案処理における基本的 な工程は，3章で示されたのと同様に，フーリエ変換 $(\mathrm{e})$, ローパスフィルター (f), 逆変換 $(\mathrm{g})$ および 2 值化処理 $(\mathrm{h})$ であるが，展開図(1)に見られるような，ステップ送りを つけるための平行四辺形への変形 $((\mathrm{b}),(\mathrm{j}))$ とカットアン ドペースト処理 $((\mathrm{c}),(\mathrm{k}))$ と, FFTを行うための画像サ イズのリサイズ処理 $((\mathrm{d}),(\mathrm{i}))$ を，それぞれ，その基本的 な工程の前後に付加している.

なお，2 值化処理を行う直前とその段階 $(\mathrm{g}),(\mathrm{h}))$ では, 罒中の対になった矢印で示されるように，図案は上下左 右に直接連続した四方送りの状態である.この後, 2 組の 矢印に注目すると, 平行四辺形への変形, カットアンド ペースト処理 $((\mathrm{j})(\mathrm{k}))$ で, ステップ送りがつく.ここで, 左右に柄が連続する位置が, 平行四辺形に変形した分量 だけ上下にシフトしていることがわかる.

ここで示した処理工程の中で, 平行四辺形への変形 ( (b), (j)) 分量が, 送りのステップ分量に相当している. したがっ て，この分量を制御すれば，辺の長さの $1 / 4,1 / 3$ などの 比率のステップ送りにも対応できる. また, この平行四 辺形への変形を, 上下から左右方向に変えれば, 送りの 方向は, 縦から横方向に変わる.

\section{5. 結 言}

斑柄のような幾何学的な罒案を元に, FFTによる画像 処理, パース (平行四辺形への変形), リサイズ, 2 值化処 理などを組み合わせることで, オリジナルのイメージを
生かした, ステップ送りの図案が, 簡単に作成できるこ とが示せた．また，パースとカットアンドペーストの方 向と分量によって, 送りの方向と分量を変化できること が示せた

このようにフーリエ変換にいくつかの画像処理を組み 合わせることで, 元のイメージを生かした送りのある多 様な基本柄が, 比較的簡単に作成することが可能になる と考えられる.

\section{謝 辞}

本展開方法を検討するにあたり, 送り付けの手法及び 図案の提供を頂いた, 株式会社島精機製作所, トータル デザインセンター，木村裕美子チーフに謝意を表す。

\section{文 献}

1. Naoki Sakai, “Tekisutairu no Dezain”, Bijutu Shuppansha (1978).

2. "Nihon no Somegata", Seigensha (2004).

3. Yuuha lizuka, Costume and Texitile, 8, 1 (2007).

4. Mikio Takagi, Haruhisa Shimoda, "Shinpen Gazou Shori Handobukku”, Toukyoudaigaku Shuppankai (2004).

5. Seiki Akama, "Gazou Shori no Kiso", Gihoudou Shuppan (2006).

6. Hironao Yamada, "Zukai Zatsugaku Dejitaru Gazou Shori", Natumesha (2006).

7. Atsushi Nakamura, Motoharu Fujigaki, Yoshiharu Morimoto, “21th NCP Conference, JSME” p.67 (1997). 